\title{
AVALIAÇÃO DISCENTE SOBRE O DESENVOLVIMENTO DOS PROCESSOS DE ENSINO E APRENDIZAGEM MEDIADOS PELAS REDES SOCIAIS
}

\author{
Everton Bedin ${ }^{1}$ \\ José Claudio Del Pino ${ }^{2}$
}

\begin{abstract}
Resumo: Estudar as redes sociais como aparatos à didática docente na ótica discente, a fim de averiguar o trabalho docente sobre as interaçóes e diálogos à luz da Sustentabilidade Ambiental com estudantes da Educaçáo Básica, foi o objetivo central deste artigo. A metodologia abordada foi de cunho exploratório, tratando-se de um estudo quali-quantitativo. Coletou-se os dados por meio de uma adaptaçáo às 5 afirmaçóes da escala de Likert, inseridas nas redes sociais. Constatou-se que os estudantes compreendem a necessidade do trabalho docente estar pautado no uso das redes sociais e a necessidade de compromisso e dedicação por parte dos mesmos frente ao trabalho docente vinculado
\end{abstract}

1 Graduado em Química Licenciatura Plena pela Universidade de Passo Fundo - UPF (2009). Especialista em Tecnologia de Informação e Comunicação na Educação - TICEDU - pela Universidade Federal de Rio Grande - FURG (2014). Mestre em Educação em Química pela Universidade Federal de Uberlândia - UFU (2012). Doutor em Educação em Ciências: química da vida e saúde pela Universidade Federal do Rio Grande do Sul - ÚFRGS (2015), visando à utilização das TICs na construção de práticas pedagógicas interdisciplinares à luz dos processos de ensino e aprendizagem na formação discente e docente. Atualmente é pós-doutorando pela Universidade Federal do Rio Grande do Sul - UFRGS - no Programa de Pós-graduação: Educação em Ciências: química da vida e saúde, professor de química na escola Cristo Rei e professor adjunto com doutorado na Universidade Luterana do Brasil - Ulbra/Canoas, onde atua como coordenador do subprojeto Pibid |química e do Laboratório de Pesquisa em Ensino de Química desta universidade. Possui experiencia na área de Química com ênfase em Química, trabalhando, principalmente, com formação docente no viés das temáticas: ensino, TICs, interdisciplinaridade, politecnia e metodologias de ensino.

2 Possui graduação em LICENCIATURA EM QUÍMICA pela Pontifícia Universidade Católica do Rio Grande do Sul (1975), graduação em QUIIMICA INDUSTRIAL pela Pontifícia Universidade Católica do Rio Grande do Sul (1975), especialização em QUìMICA pela Universidade de Passo fundo (1978), especialização em ENSINO DE QUÍMICA pela Universidade de Caxias do Sul (1988), mestrado em Mestrado em Ciências Biológicas-Bioquímica pela Universidade Federal do Rio Grande do Sul (1984), doutorado em Engenharia de Biomassa pela Universidade Federal do Rio Grande do Sul (1994) e pós-doutorado pela Universidade de Aveiro-Portugal (2004). Atualmente é professor associado da Universidade Federal do Rio Grande do Sul. ProfessorOrientador do PPG Educação em Ciência Química da Vida e Saúde e do PPG Química ambos da Universidade Federal do Rio Grande do Sul. Bolsa de Produtividade em Pesquisa do Conselho Nacional de Desenvolvimento Científico e Tecnológico. Tem experiência acadêmica na área de Educação, com ênfase em Educação Química, atuando principalmente nos seguintes temas: formação de professores, ensino de química, material didático, currículo de química e informática educativa. 
às tecnologias. Destarte, a ação deste estudo indica iniciativa e estímulo aos docentes para buscarem a qualificação e a atualização dos processos ensino e aprendizagem via uso das redes sociais.

Palavras-chave: Redes Sociais. Trabalho Docente. Ensino-Aprendizagem.

\title{
EVALUATION OF THE STUDENT ABOUT THE TEACHING AND LEARNING PROCESSES MEDIATED BY SOCIAL NETWORKS
}

\begin{abstract}
Study the social networks as apparatuses in the didactic teaching from the perspective of the student, to ascertain teachers' work on interactions and dialogues in the light of Environmental Sustainability with students Basic Education, was the central objective of this article. The methodology discussed was exploratory, in the case of a qualitative and quantitative study. Data were collected through 5 statements adaptation to Likert scale, embedded in social networks. It was found that students understand the necessity of teaching be guided in the use of social networks and need for commitment and dedication from the latter against the working bound teacher to technologies. Thus, the action of this study indicates initiative and encouragement to teachers to seek qualification and updating of the teaching and learning processes via use of social networks.
\end{abstract}

Keywords: Social Networks. Teaching Work. Teaching and Learning.

\section{INTRODUÇÃO}

$\mathrm{Na}$ educação, momentos de revolução e reestruturação nas práticas docentes ocorrem de forma exacerbada na tentativa de qualificar os processos de ensino e aprendizagem para que o estudante possa aprender de forma significativa e satisfatória. Neste sentido, as tecnologias, em especial as redes sociais, possuem um papel expressivo para transformar e mudar este cenário, pois são consideradas mecanismos de aproximação entre os sujeitos, podendo, de certa forma, auxiliar na construção do conhecimento e na troca de experiências e opiniões sobre diversas formas e conceitos.

Este processo decorre da concepção de que as redes sociais são atrações para diversas pessoas que, indiferente do lugar, se encontram conectadas, dialogando e interagindo de múltiplas formas. O interessante deste desenho é que, além da possibilidade de dialogar e proliferar informações, os usuários das redes podem postar fotos, vídeos e comentários, utilizando-as, muitas vezes, para forjar saberes e conhecimentos sobre múltiplas instâncias.

Corroborando, Bedin e Del Pino (2017b, p. 234) afirmam que as tecnologias, mesmo sendo utilizadas como mecanismos de entretenimento e proliferação de informação, têm sido utilizadas recentemente pelos professores como uma maneira de "qualificar os processos de ensino e aprendizagem". De outra forma, pela conectividade oferecida pela rede, assim como a facilidade da comunicação, estas "possuem, além de uma importância social de utilização, de partilha e de vinculação, 
uma maneira de relacionar o conhecimento científico com conhecimento sociocultural".

Assim, o uso das redes sociais é intrinsecamente importante para a ação docente, já que alguns professores consideram que o conhecimento é construído socialmente por meio de processos, sendo ampliado pela cooperação, colaboração e interação (MOLINA; SALES, 2008). Nesta linha, Hodgins (2007) reflete que o aprendizado é uma habilidade social que deve ser continuamente melhorada, isto é, o estudante tem papel fundamental na construção do próprio saber, uma vez que a efetivação do mesmo ocorre quando o indivíduo elabora seu próprio entendimento a partir das suas interações.

Nesta vertente, Chatti et al. (2006) expõem que o aprendizado não é a ligação entre pessoas e conteúdos, mas a conexão de pessoas com outras pessoas para dar suporte à construção colaborativa do conhecimento. Assim, as redes sociais são mecanismos fundamentais para os estudantes dialogarem de forma aberta e autêntica, fortalecendo o aprendizado em um contexto socialmente acessível, oferecendo diversas formas de interação entre os sujeitos, por exemplo, discussões, comentários, críticas, sugestões. Logo, as redes sociais atuam como um veículo de aprendizagem docente e discente e, na medida em que oferecem diversas formas de interação, facilitam a colaboração e a comunicação entre os sujeitos fora dos muros da escola.

Nesta vertente, acredita-se que as redes, em especial o Facebook, apresentam um intenso crescimento à aprendizagem dos sujeitos, pois "a aderência a esses espaços elege muitos aspectos para reflexão e discussão, como a necessidade de manter-se conectado a todo instante, a facilidade de estabelecer novas relações, a comunicação em tempo real e a sociabilidade" (MARCON et al., 2012, p. 3).

O professor, na utilização das redes sociais para a qualificação dos processos de ensino e aprendizagem, precisa centrar sua metodologia na afetividade, na dialogicidade e na colaboratividade, pois estas são fatores fundamentais para que os trabalhos de forma virtual possam ser desenvolvidos de forma satisfatória. Além do mais, o professor precisa entender que, quando trabalha com as tecnologias, carece de disponibilizar vários recursos virtuais de aprendizagem aos estudantes, a fim de favorecer e qualificar a aprendizagem e o entrosamento entre os sujeitos.

Corroborando, Masetto (2006, p. 144) afirma que "haverá necessidade de variar estratégias tanto para motivar o aprendiz como para responder aos diferentes ritmos e formas de aprendizagem, pois nem todos aprendem do mesmo modo e no mesmo tempo". Dentro deste contexto, entende-se que a conectividade, a interação e a comunicação entre os sujeitos envolvidos nesse processo são fundamentais para um bom trabalho. Portanto, este artigo tem o objetivo de apresentar reflexões críticas sobre as concepções e as avaliações de estudantes do ensino médio quando instigados a pensar criticamente sobre a ação de o professor mediar os processos de ensino e aprendizagem a partir do Facebook.

A investigação do presente trabalho justifica-se no sentido de entender a visão do educando sobre as atividades que interferem em sua formação, em especial, 
com o auxílio do Facebook, uma vez que este permite ao professor definir estratégias pedagógicas inovadoras que incluem a utilização de múltiplas ferramentas, as quais possibilitam um trabalho flexibilizado no contexto da aprendizagem; uma forma individual e cooperativa de desenvolver trabalhos que instigam os estudantes às ações de pensar, cooperar, partilhar e a construir o seu próprio conhecimento.

\section{MARCO TEÓRICO SOBRE A TEMÁTICA}

Ao considerar as Tecnologias de Informação e Comunicação (TICs) como mecanismos proliferadores de ideias e concepções na era da comunicação e do conhecimento, assim como meios de facilitar o trabalho do professor de formas e maneiras diferenciadas para este conduzir os processos de ensino e aprendizagem, Recuero (2009) relata que o estudo das redes sociais vem permeando a ciência desde o início do século passado, afinal estas redes são um conjunto finito de atores indivíduos - e as relações (ou conexões) entre eles podem ser compreendidas como um caminho para a construção de práticas integradas e integradoras, conectando o conhecimento social com o saber científico (WASSERMAN; FAUST, 1994).

Estas concepções sobre as tecnologias apresentam o real papel de seu uso nas escolas, uma vez que servem para aproximar os sujeitos da ensinagem e qualificar não apenas o relacionamento entre eles, mas o processo de quantificação e proliferação dos conhecimentos construídos ao longo do percurso. Assim, Masetto (2006, p. 153) afirma que as tecnologias devem ser usadas para além da valorização da aprendizagem e da formação permanente, sendo utilizadas para "qualificar a pesquisa de informação básica e novas informações, o debate, a discussão, o diálogo, o registro de documentos, a elaboração de trabalhos, a construção da reflexão pessoal, a construção de artigos e textos".

Nesta perspectiva, entende-se, na visão de Bedin e Del Pino (2017b, p. 237), que:

[...] a incorporação das inovações tecnológicas só tem sentido se estas, de alguma forma, contribuírem para a melhoria da qualidade do ensino e o desenvolvimento do trabalho interdisciplinar. A simples presença de novas tecnologias na escola não é, por si só, garantia de maior qualidade na educação, pois a aparente modernidade pode mascarar um ensino tradicional baseado na recepção e na memorização de informações.

Acredita-se que as redes sociais estão aliadas aos processos de ensino e aprendizagem, se configurando como aparatos inovadores na troca de saberes e construção de conhecimento, possibilitando novas estratégias de ensino aos professores. Silva e Cogo (2007) ajuízam que essas tecnologias estão transformando a maneira de ensinar e de aprender nas escolas e fora delas, oferecendo maior versatilidade, interatividade e flexibilidade de tempo e de espaço. Corroborando a essas concepções, Balbino e Anacleto (2011, p. 5) refletem que o ambiente das redes sociais na Internet configura-se como um potencial para a extensão de práticas educativas; Werhmuller e Silveira (2012, p. 595) afirmam que este espaço virtual "abre a oportunidade de alunos e professores interagirem entre si, trocando 
informações, experiências pessoais e profissionais, compartilhando conhecimentos de forma colaborativa, dinâmica".

Segundo Capobianco (2010), as TICs oferecem recursos para favorecer e enriquecer as atividades e aplicações nos processos educacionais. Assim, adotá-las fora da realidade da sala de aula é uma possibilidade para complementar a educação formal. Lemos (2004), ainda, afirma que as TICs são resultados de convergências tecnológicas que transformam as antigas metodologias por meio de revisões, invenções ou junções, tornando-se evidente a situação de que o uso delas provoca mudanças impactantes e significativas na construção sociocultural do estudante, desdobrando-se nos meios econômico, científico e político.

Nesta teia, o Facebook, utilizado como rede social para a investigação neste artigo, se justifica pela ampla capacidade de proporcionar a relação entre milhões de pessoas e, exclusivamente, disponibilizar a relação entre professor-estudante. Afonso (2009, p. 43) entende o Facebook como "uma rede social que reúne pessoas a seus amigos e àqueles com quem trabalham, estudam e convivem", uma vez que os usuários da rede criam perfis que contêm fotos e listas de interesses pessoais, trocando mensagens privadas e públicas entre si e participantes de grupos de amigos.

Esta rede social proporciona uma vasta lista de ferramentas e aplicações que permitem aos usuários comunicar e partilhar informação, assim como controlar quem pode assentir informação específica ou realizar determinadas ações (EDUCAUSE, 2007). Nesta linha, Patrício e Gonçalves (2010) afirmam que o Facebook é, provavelmente, o principal sítio de encontro, comunicação, partilha e interação de ideias e assuntos de interesse comum, entre os estudantes.

Rosa e Cecílio (2010, p. 6) confirmam esta ideia ao afirmarem que:

Usar as tecnologias, sobretudo via redes, ultrapassa os limites impostos pelo espaço-tempo. Na prática pedagógica, essa constatação implica redefinir a formação do profissional da educação de forma que este, ao atuar no ensino superior, compreenda as potencialidades das TICs, pela apropriação e uso delas. Afinal, estas podem dar suporte para a comunicação entre educadores, pais, membros da comunidade externa, e criar um fluxo de informações; trocar experiências que fundamentem a tomada de decisões, realizar atividades colaborativas cuja produção permita enfrentar os problemas da realidade, desenvolver projetos inovadores relativos à gestão administrativa e pedagógica; enfim, favorecer a construção do conhecimento pelos alunos e a respectiva aprendizagem.

Neste sentido, o Facebook se constitui como um espaço para o interrelacionamento do professor com seus alunos e de ambos com o conhecimento, pois, no momento em que o professor possibilitar aos estudantes uma forma de continuar o trabalho da sala de aula de modo virtual, algo que lhe atrai e faz parte de seu contexto, podendo contorná-lo/adaptá-lo como um ambiente virtual para a aprendizagem, transformando a aprendizagem em uma atividade social, aumentará a satisfação do estudante em produzir e compartilhar conhecimento, uma vez que o maior valor das redes sociais é justamente aquele para a qual foram criadas: manter 
contato entre as pessoas que no caso da educação é o de manter contato entre professores e alunos, professores entre si e alunos entre si (HARO, 2008).

Não obstante, percebe-se que a vantagem de utilizar o Facebook para desenvolver atividades de cunho pedagógico nas escolas é, justamente, o fato de ele proporcionar características de centralização de informações, isto é, uma forma que permite o estudante navegar em busca de informações que se ramificam em diversos saberes, sem sair da sua página na rede. Além do mais, permite o estabelecimento de contatos, conexão entre diversos usuários, aquisição de conhecimento e discussões pautadas em diversos assuntos, atualizadas e concentradas no momento real de aprender, uma vez que as redes sociais são aplicações que suportam um espaço comum de interesses, necessidades e metas semelhantes para a colaboração, a partilha de conhecimento, a interação e a comunicação (PETTENATI et al., 2006; BRANDTZAEG et al., 2007).

Destaca-se, ainda, que o Facebook representa uma nova intenção de partilhar contatos, informações e conhecimentos, sendo uma das redes sociais mais utilizadas em todo o mundo para interagir socialmente. Assim, as interações que surgem quando o professor usufrui da rede para construir conhecimento com seus estudantes são, de fato, necessárias à investigação, pois pela participação em grupos de discussão e a troca de ideias que surgem neste meio se configura, basicamente, a identidade do sujeito.

Por fim, diante das colocações de Patrício e Gonçalves (2010), é sagaz relembrar que o Facebook é tido não só como um canal de comunicação e um destino para pessoas interessadas em procurar, partilhar ou aprender sobre determinado assunto, mas igualmente como um meio de oportunidades para o ensino, uma vez que se apresenta como uma ferramenta popular e de fácil manuseio, não necessitando de desenvolvimento interno ou de aquisição de software, tornando-se útil para alunos, professores e funcionários.

\section{DESENHO DA PESQUISA}

O trabalho teve como objetivo entender e refletir sobre as concepções dos estudantes frente ao trabalho docente desenvolvido na rede, isto é, entender a visão dos estudantes sobre pontos importantes e relevantes na forma didática de o professor trabalhar os conteúdos curriculares com o auxílio do Facebook. Para tanto, após um trabalho árduo de forma presencial e virtual sobre Sustentabilidade Ambiental que durou cinco meses, o professor da disciplina de Seminário Integrado de uma escola pública localizada no centro norte do estado gaúcho, inseriu cinco afirmações no Facebook, as quais derivaram, de forma adaptada, da escala de Likert.

Para tal ação, o professor titular da disciplina organizou dentro do seu próprio perfil do Facebook um grupo fechado para desenvolver esta atividade. Assim, como o professor é amigo dos alunos na rede social, acabara por inserir os 41 alunos das duas turmas do Segundo Ano do Ensino Médio onde desenvolveu as atividades. 
De acordo com Brandalise (2005, p. 4), "as escalas de Likert, ou escalas Somadas, requerem que os entrevistados indiquem seu grau de concordância ou discordância com declarações relativas à atitude que está sendo medida". Assim, a escolha pelas informações se enquadrarem na derivação da escala de Likert surgiu da reflexão sobre a realidade da sala de aula, isto é, a escala, dependendo de sua pontuação, aponta entre quatro e cinco categorias ordinais, transitando de concordar totalmente a discordar totalmente da afirmação.

Alexandre et al. (2003) explicam a complexidade de uma escala de Likert simétrica e com um número ímpar de categorias, pois a categoria central (não concordo e nem discordo) representa uma indecisão. Portanto, para desviar-se desta indecisão, adaptou-se a escala de Likert, transitando de sempre até nunca, sem deixar centralidade de indecisão, uma vez que buscou-se analisar se os alunos validavam positiva ou negativamente a ação do professor.

Ainda, destaca-se que a análise e interpretação dos dados coletados na rede via adaptação da escala de Likert frente as cinco afirmações disponibilizadas pelo professor, foi realizada pelo pesquisador, responsável pela disciplina. Esta afirmação é importante na medida em que nos gráficos abaixo aparecem reflexões sobre o público-alvo e as colocações destes; estas reflexões nascem da observação e do convívio com a turma.

A atividade que teve como base o grupo na rede foi desenvolvida pelo professor no decorrer do ano 2015, tendo validação ao seu trabalho na visão do estudante em 2016. Ou seja, a atividade se propagou ao longo do último semestre do ano 2015 como fonte avaliativa da determinada disciplina, mas as afirmações que são apresentadas neste trabalho foram instigadas e validadas ao uso das redes sociais pelos estudantes no ano de 2016. As afirmações disponibilizadas pelo professor foram respondidas pelos estudantes dentro de uma semana.

\section{RESULTADOS E DISCUSSÁO}

As afirmações que o professor disponibilizou no grupo da rede foram visualizadas e respondidas pelos 41 estudantes que nela estavam inseridos; logo, os dados apresentados a seguir são referentes a totalidade da amostra, não a uma parcela do grupo. Do mesmo modo, as afirmações, as quais foram elaboradas pelo professor, a fim de coletar as ideias, concepções e percepções dos estudantes sobre a importância e relevância do trabalho desenvolvido durante o ano de 2015, continham as opções: às vezes, poucas vezes - aqui destaca-se a leitura para quase nunca-, sempre, quase sempre e nunca, que foram adaptadas a partir da escala de Likert de cinco pontos.

Estas afirmações não existem unicamente para entender como o trabalho do professor, quando interligado ao uso das tecnologias, muda o cerne da aprendizagem do estudante, mas serve como indicador de mudança nas atitudes de como o mesmo participa das atividades, troca ideias com os colegas e, dentre outras, expõe suas concepções e percepções. A figura 1, por exemplo, apresenta uma das afirmações e as categorias disponibilizadas na rede. 
Figura 1: Opção disponibilizada na rede e as afirmações adaptadas sobre a escala de Likert.
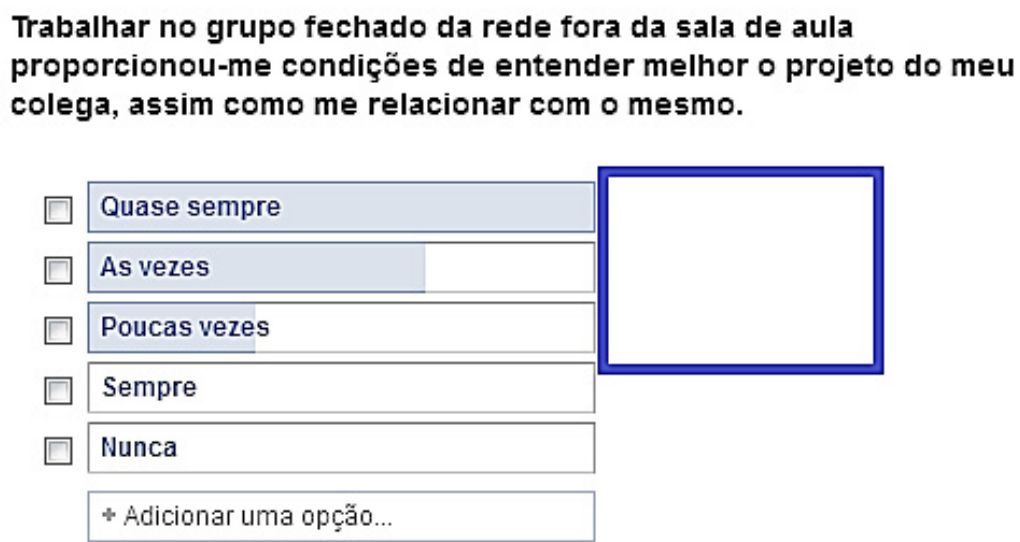

Curtir - Comentar - Compartilhar

Fonte: Dados da pesquisa.

A adaptação sobre a escala de Likert foi aplicada ao número total de estudantes, garantindo maior confiabilidade da análise para a qualificação e a quantificação dos dados. Dentre os sujeitos, 18 são do sexo feminino e 23 do sexo masculino; para intensificar a reflexão sobre os dados, optou-se em apresentar os resultados desta pesquisa, os quais estão esquematizados em gráficos e percentuais, na totalidade dos 41 estudantes, não os separando por diferença de gênero.

A primeira afirmação que o professor disponibilizou na rede foi: "Dialogar com os colegas sobre Sustentabilidade Ambiental no grupo fechado na rede foi bom, porque consegui expor minhas ideias e concepcões, o que não conseguia fažer em sala de aula”. Analise o gráfico 1 . 
Gráfico 1: Indicação dos estudantes sobre a $1^{a}$ afirmação postada na rede

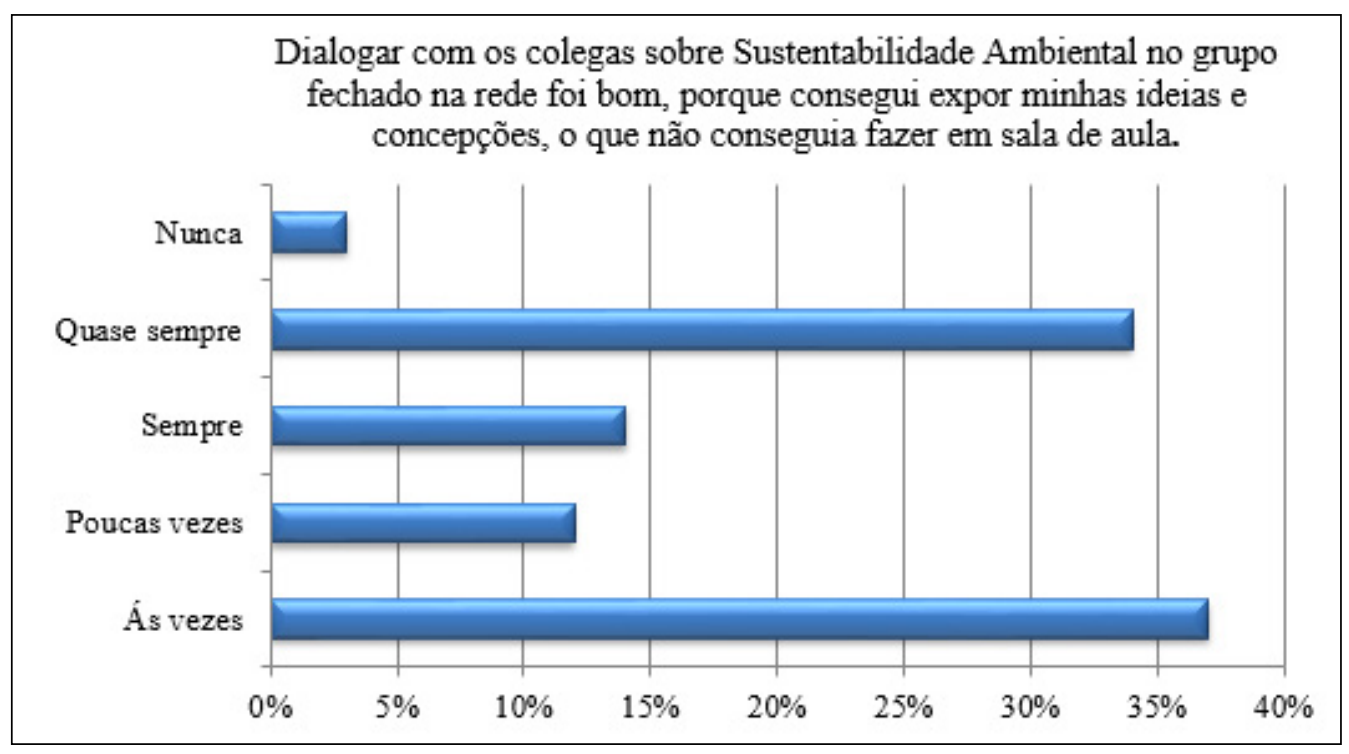

Fonte: Dados da pesquisa.

Frente à afirmação, pode-se perceber que mais de 50\% dos estudantes afirmam que Quase sempre e Âs vezes com o auxílio da rede conseguiam expor suas opiniões e ideias. Isso pode derivar do entendimento de que com a rede o estudante se sente mais apto, crítico e seguro de seus conceitos, sem medo ou dificuldade de expô-los ou defendê-los, uma vez que a aprendizagem é uma situação na qual duas ou mais pessoas aprendem ou tentam aprender algo juntas (DILLENBOURG, 1999).

Percebe-se, também, que 14\% dos estudantes afirmam Sempre conseguirem expor suas ideias, enquanto que $12 \%$ retificam-se em Poucas vezes. Isso é resultado de uma sala de aula heterogênea, com pessoas e opiniões próprias, enquanto outras em processo de construção, ou seja, algumas com facilidade de coexistência interativa e/ou diferentes sugestões ou críticas em meio às divergências que emergem na rede. Moran (2002, p. 24) compreende que o conhecimento ocorre "fundamentalmente no processo de interação, de comunicação", pois trabalhar de modo colaborativo, compartilhando conhecimentos múltiplos, está se tornando cada dia mais necessário para os afazeres escolares, isto quando compartilhado aos princípios da educação problematizadora, cujo intuito é transformar o sujeito cognoscente em intérprete-autor (ABEGG; BASTOS; MULLER, 2010).

Do mesmo modo, Bedin e Del Pino (2017b, p. 238) afirmam que:

Assim, ao trabalhar com a rede como aparato de proliferação de informação e mecanismo de estudo e aprendizagem de cunho interdisciplinar propõese a ressignificação para o ensino, pois as redes nos livram das escalas micro e macro - família, grupo, instituições, nação - substituindo-as por conectividade; a hierarquia e o poder dão lugar a associações e conexões. 
A segunda afirmação que o professor disponibilizou no grupo, refletia sobre a importância da rede para o entendimento dos estudantes frente aos projetos dos colegas desenvolvidos na disciplina de Seminário Integrado. Nesta vertente, e analisando o gráfico 2, pode-se perceber que mais da metade dos estudantes compreendem a necessidade da rede para entender o projeto do colega, uma vez que a troca de saberes e o intercâmbio das informações entre eles era diário, sendo a conversação de forma contínua, onde os mesmos podiam, em meio às dúvidas, questionar, sugerir e criticar.

Gráfico 2: Indicação dos estudantes sobre a $2^{\mathrm{a}}$ afirmação postada na rede.

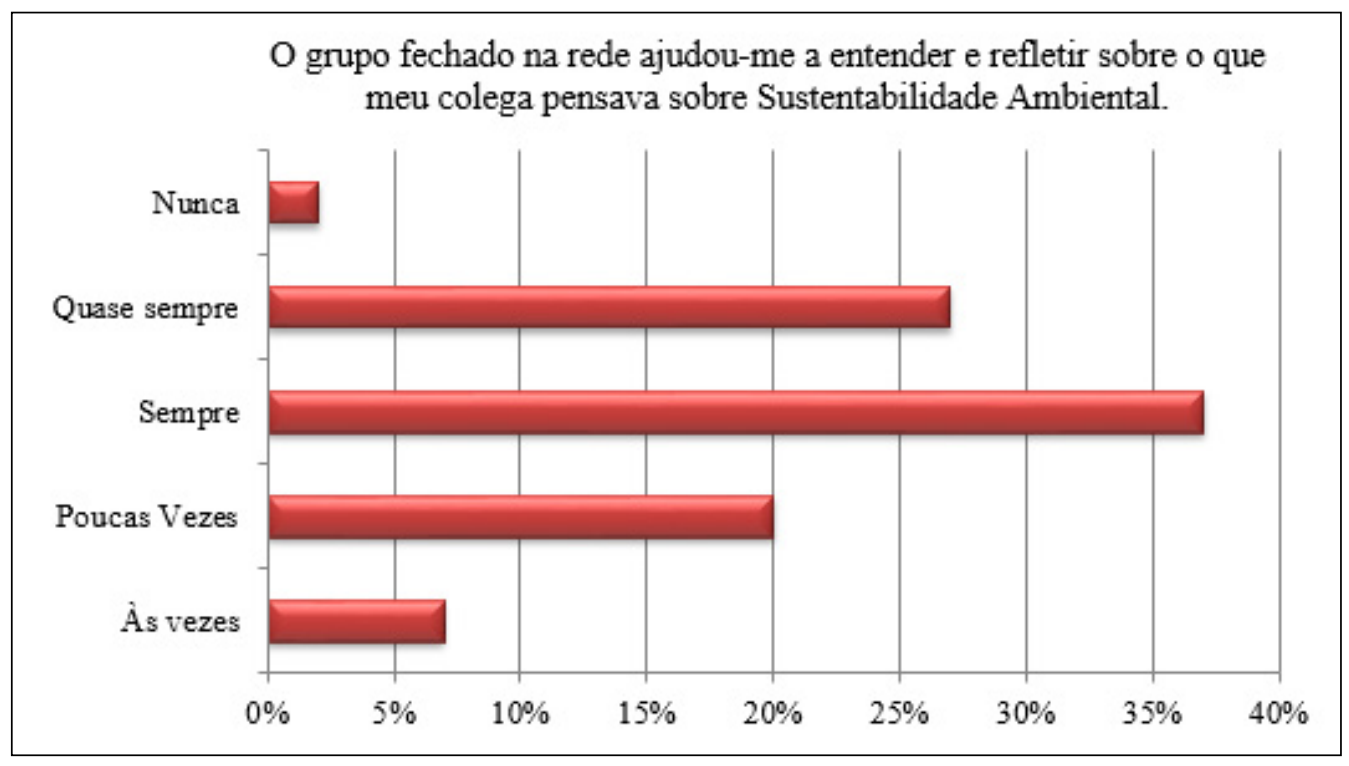

Fonte: Dados da pesquisa.

Tapscott e Williams (2007, p. 299) afirmam que a natureza do próprio trabalho está mudando; "ele se tornou cognitivamente mais complexo, mais baseado em equipes e colaborativo, mais dependente de habilidades sociais, mais pressionado pelo tempo e baseado em competência tecnológica, mais móvel e menos dependente da geografia”. Assim, percebe-se que os processos de ensino e aprendizagem que ocorrem na rede apresentam como respaldo a teoria sócio construtivista, refletida por Vygotsky (1998), a qual traz como ideia central a de que os processos psicológicos superiores ocorrem primeiro nas relações sociais; processos intermentais ou processos interpsicológicos, sendo regulados e controlados pela interação, que, no caso das redes sociais, são as interações entre os estudantes e o professor.

Entender o outro, a fim de construir concepções e conhecimento na cooperação, demanda tempo e criticidade, pois a internalização é um processo gradual e progressivo, no qual o ser humano cria e modifica o funcionamento intramental. Assim, o grupo na rede possibilitou, além de trocas de ideias, reflexão, 
argumentação e defesa crítica-reflexiva sobre a temática Sustentabilidade Ambiental, a inter-relação entre colegas de modo virtual, pois "o mundo educativo não pode permanecer alheio aos fenômenos sociais como este, que está mudando a forma de comunicação entre as pessoas" (HARO, 2010, p. 1).

Nesta interface, acredita-se, assim como Bruno (2010, pp. 208-209), que a formação por meio da aprendizagem não é decorrente de "um processo estanque, linear e único, marcado por apenas uma forma de aprender", mas na medida em que o "ser humano se faz e se refaz", uma vez que "os indivíduos se adaptam, mas não se conformam de que a flexibilidade na aprendizagem é imensurável e possui elementos desconhecidos até para o próprio sujeito aprendente".

Quando o professor apresentou a terceira afirmação, a qual condizia sobre o auxílio das tecnologias para entender melhor a concepções do outro, dialogando e construindo saberes fora dos muros da escola, percebeu-se que os estudantes atrelam as tecnologias como meio de trocar e construir conhecimentos. Observe o gráfico 3.

Gráfico 3: Indicação dos estudantes sobre a $3^{a}$ afirmação postada na rede.

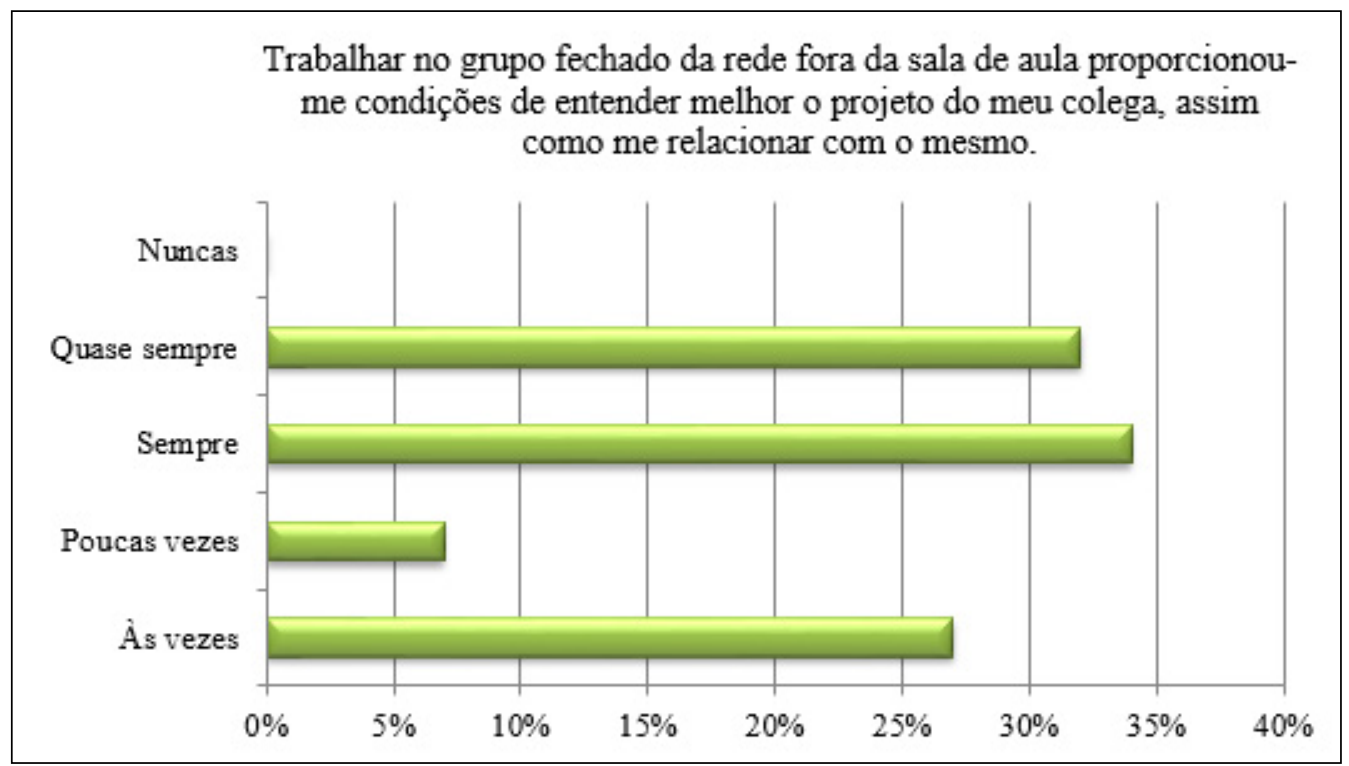

Fonte: Dados da pesquisa.

As categorias Quase sempre e Sempre foram as mais mencionadas pelos estudantes, isto é, as tecnologias proporcionaram um momento entretido e diferente para os estudantes dialogarem sobre seus projetos, de conhecerem melhor o trabalho do colega, de opinar, criticar e refletir sobre o intercâmbio de ideias que estava nascendo na rede; logo, a relação com o outro e o entendimento sobre o trabalho aconteceram de forma coesa e assídua, pois, igualmente como as interações aconteceram de forma dinâmica, com conflito de ideias e lutas de 
interesse, o diálogo se estendeu de forma qualitativa e construtiva, como, por exemplo, pode ser analisado na figura 2.

Figura 2: Alguns fragmentos extraídos da rede em relação ao trabalho desenvolvido.

\begin{tabular}{|c|c|c|}
\hline \multicolumn{2}{|r|}{$\begin{array}{l}\text { Individualmente, responda a pergunta: } \\
\text { O que é Sustentabilidade Ambiental e de que forma o vértice da pesquisa } \\
\text { se enquadra na Sustentabilidade Ambiental? }\end{array}$} & $\begin{array}{l}\text { 1. A minha opinião frente ao trabalho desenvolvido no decorrer do ano de } \\
2015 \text { sobre Sustentabilidade Ambiental, considerando a ideia de utilizar } \\
\text { as Redes Sociais (Facebook) e a interdisciplinaridade (Áreas do } \\
\text { Conhecimento) para qualificar o ensino-aprendizagem é: }\end{array}$ \\
\hline I $\mathrm{Cu}$ & E Comentar & Curtir Comentar \\
\hline (1) 8 & $\checkmark$ Visualizado por 51 & 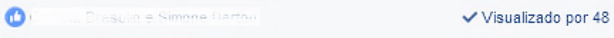 \\
\hline$=$ & 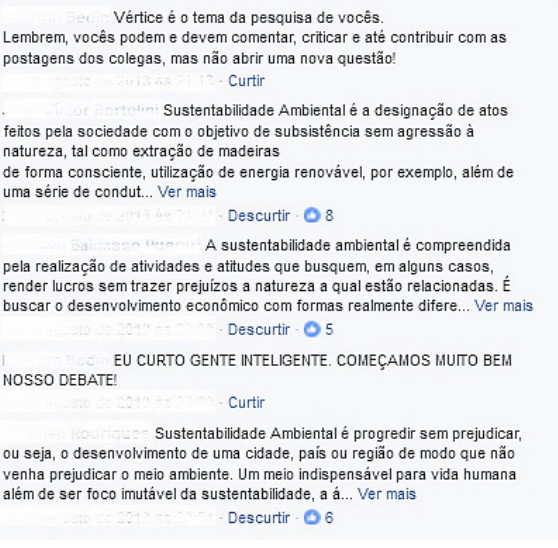 & 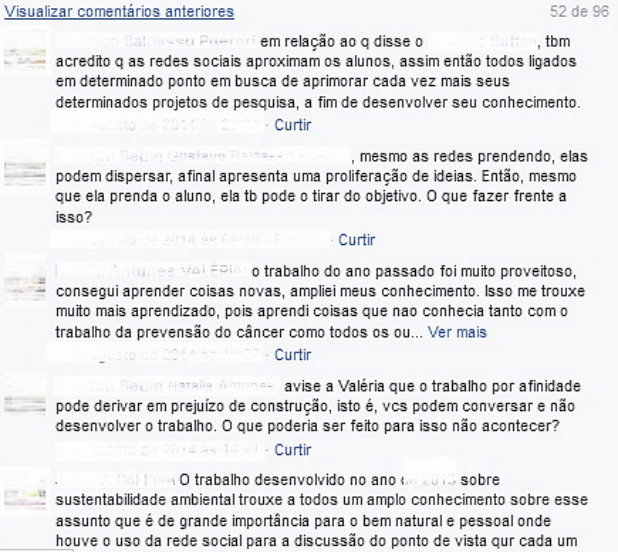 \\
\hline
\end{tabular}

Fonte: Dados da pesquisa.

Em virtude dos fatos, o professor instigou os estudantes a refletirem sobre a quarta afirmação: Enquanto dialogava com meus colegas na rede, consegui favorecer a minha construção ética enquanto pessoa cultural e social, pois, assim, consegui aprender de forma mais ampla e significativa. Analisando o gráfico 4, pode-se perceber que, em média, 50\% dos estudantes afirmam que Sempre que dialogavam no grupo cresciam de forma social e cultural, uma vez que a comunicação é princípio inicial na formação do sujeito. 
Gráfico 4: Indicação dos estudantes sobre a $4^{a}$ afirmação postada na rede.

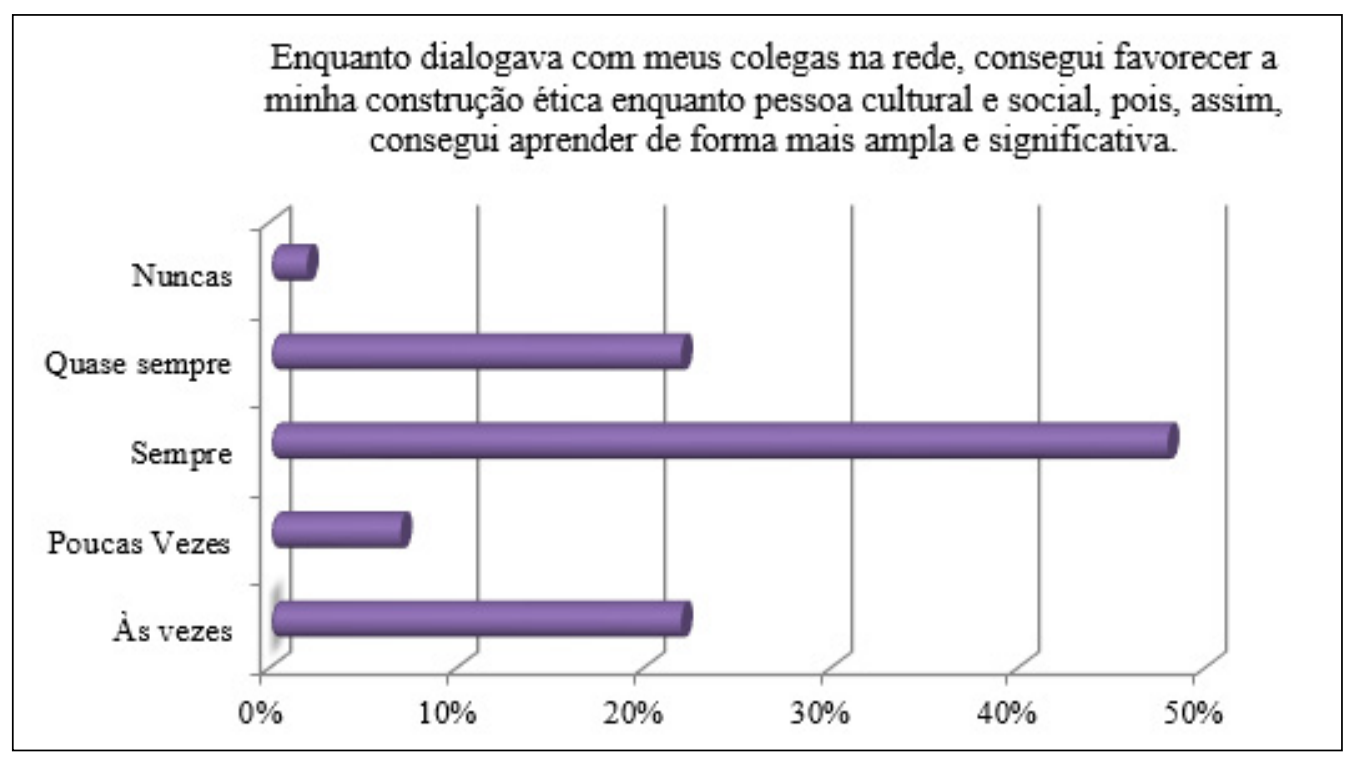

Fonte: Dados da pesquisa.

Assim, corrobora-se com as palavras de Werhmuller e Silveira (2012) quando estes refletem que o conteúdo que não é assimilado, ou fica com alguma pendência de entendimento em sala de aula, acaba sendo revisado e reforçado nestes ambientes por meio de discussões e trocas de informações de forma criativa e dinâmica, despertando o interesse dos alunos em pesquisar além do assunto; a curiosidade também é um fator que pode ocorrer durante estas reuniões virtuais.

As tecnologias, especialmente as redes sociais, reforçam a ideia de que o aprendizado deve ocorrer em um contexto socialmente aberto e que ofereça diversas formas de interação, como discussões, comentários e criação conjunta de recursos educacionais. Além do mais, Bedin e Del Pino (2017b, p. 238) afirmam que investir no uso das TICs em sala de aula é:

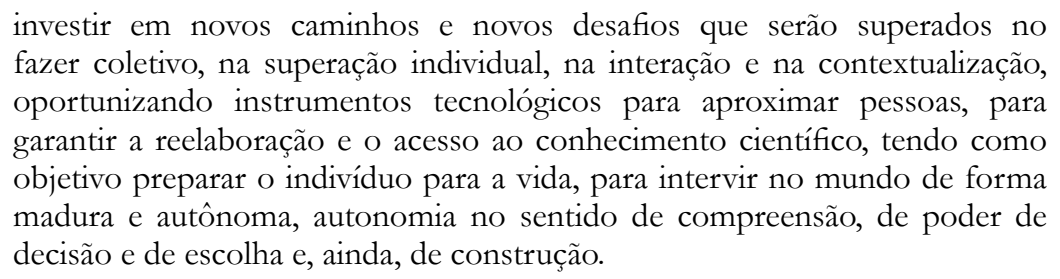

A última afirmação postada pelo professor na rede teve por objetivo fazer com que os estudantes percebessem a figura do professor para o desenvolvimento de uma atividade no viés das tecnologias. Para tanto, o professor considerou a seguinte afirmação: Percebi, com o trabalbo do professor, que para usar uma tecnologia, o grupo fechado, por exemplo, é necessária intrinsecamente a presença do professor, pois ele me dá 
força e me instiga à continuar as atividades. Analise o gráfico 5 para entender a percepção dos estudantes.

Gráfico 5: Indicação dos estudantes sobre a $5^{\mathrm{a}}$ afirmação postada na rede.

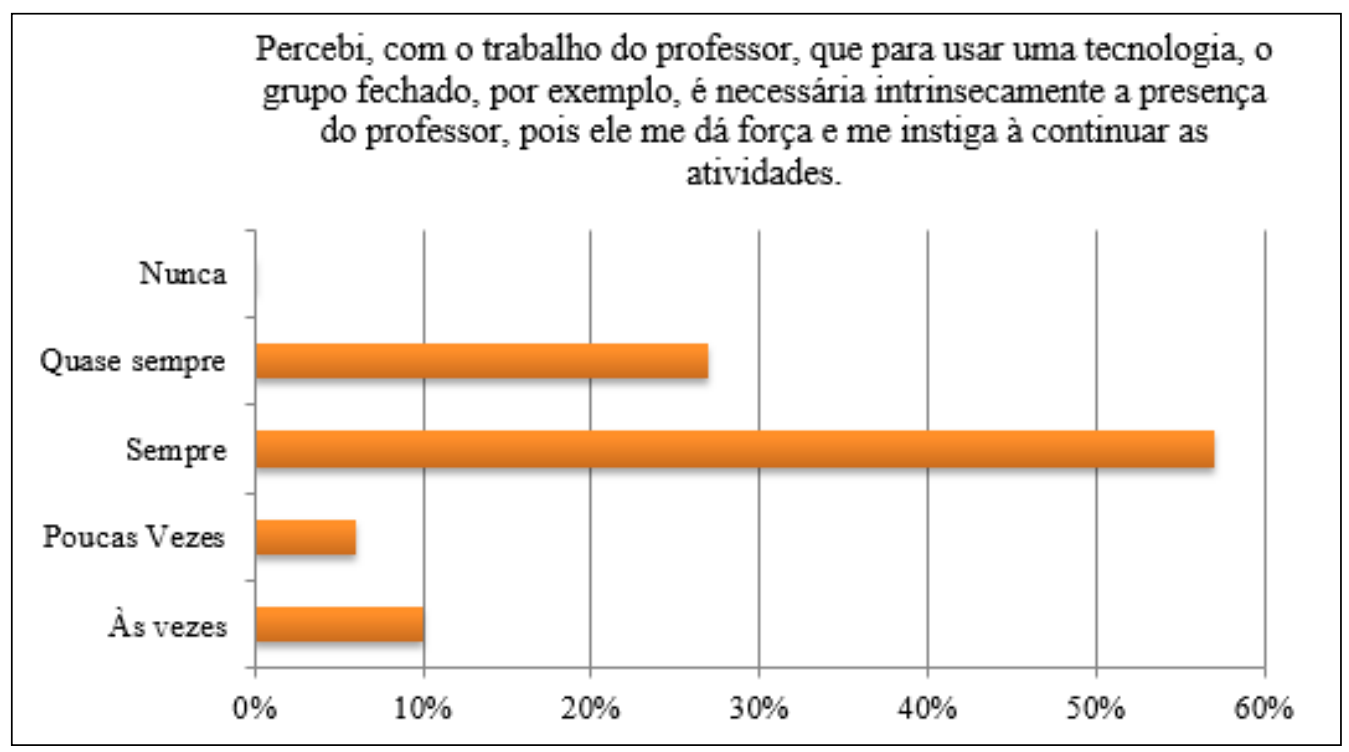

Fonte: Dados da pesquisa.

Analisando o gráfico, é percebível que os estudantes compreendem a importância e relevância da figura do professor no momento de desenvolver atividades de aprendizagem em meio às tecnologias, pois o mesmo torna-se figura ímpar neste processo, dialogando, instigando e chamando os estudantes a participação; o uso das tecnologias serve para aproximar o estudante do conhecimento, proporcionando-lhe habilidades e competências em meio à aprendizagem.

Ainda, cabe lembrar que a tecnologia pode auxiliar o professor para melhorar sua aula, deixando-a mais atraente e pertinente, não desclassificando a importância do conhecimento; o saber científico do professor é o suporte para ressignificação do saber comum dos estudantes; logo, deve estar sempre em primeiro lugar, motivando o estudante para seu domínio teórico e prático, pois as TICs são aliadas deste processo, facilitando à absorção, a internalização, a reestruturação e o relacionamento do conhecimento pelos estudantes.

Portanto, tem-se que uma das vantagens em utilizar as redes sociais, na visão de Bedin e Del Pino (2017b, p. 238), é sua utilização como

apoio para enriquecer o momento pedagógico, negando-se a transmissão de ideias, já que apresenta uma multiplicidade de ferramentas de comunicação e trabalho, capazes de fazer com que os estudantes aprendam em meio à comunicação e a interatividade via condições de suporte para a dinâmica necessária à colaboração e a socialização. 
Alberti (2006, p. 122) afirma que "as TICs utilizadas como recursos educativos assumem um papel importantíssimo nesse processo, uma vez que têm como função estabelecer a intermediação entre o conhecimento científico e os alunos/docentes". Portanto, a intervenção docente precisa ocorrer no conteúdo, assim como na coerência do uso das tecnologias, desenvolvendo um trabalho contínuo no aprimoramento do saber em sala de aula, tornando-a mais atrativa, envolvente, dinâmica, animadora e efetiva. Para tanto, a formação docente deve ser permanente.

Neste aporte, Litwin (1997) reflete e ressalva sobre a importância do uso das tecnologias digitais na educação, percebendo a exigência de mecanismos que favoreçam a amplitude da visão e postura sistêmica na relação com o aprendizado.

A tecnologia posta à disposição dos estudantes tem por objetivo desenvolver as possibilidades individuais, tanto cognitivas como estéticas, através das múltiplas utilizações que o docente pode realizar nos espaços de interação grupal. Se nas aulas resolvemos problemas autênticos e não de "brinquedo" isto é, se propomos problemas reais para gerar processos de construção do conhecimento, somos conscientes de que utilizamos as tecnologias que foram transformando as mentes dos estudantes ao longo de sua vida, enquanto os alunos vêm à classe com todas suas experiências vitais sobre os ombros. Por outro lado, a criação dos novos espaços de simulação atinge a cultura escolar e faz-nos traçar os contextos reais de onde se constrói efetivamente o conhecimento. Desconhecer a urdidura que a tecnologia, o saber tecnológico e as produções tecnológicas teceram e tecem na vida cotidiana dos estudantes nos faria retroceder a um ensino que, paradoxalmente, não seria, tradicional, e sim, ficcional (LITWIN, 1997, p. 10).

Diante dos fatos, destaca-se a ideia inerente de pensar e instigar a emersão da necessidade para o docente em buscar uma formação adequada que o oriente no próprio trabalho com estes novos mecanismos de aprendizagem, uma vez que os estudantes enfatizam um saber mais veloz e coerente ao berço das tecnologias. Afinal, de acordo com Bedin e Del Pino (2017b, p. 239), "a possibilidade de interagir e aprender através das ferramentas tecnológicas implica rever todos os papéis dos envolvidos nos processos de ensino e aprendizagem e, também, da metodologia utilizada para a promoção dessa aprendizagem".

\section{CONSIDERAÇÓES FINAIS}

Diante das análises e reflexões apresentadas neste artigo, pode-se perceber que a atividade na rede foi, de fato, enriquecedora para os estudantes quanto para o professor, pois se desenvolveu de forma ímpar e única no que diz respeito a relação com o outro, a construção do saber, a troca de conhecimento e, dentre outros, a relação com os trabalhos em sala de aula. Assim, os processos de ensino e aprendizagem configurados pelo professor na rede podem favorece um aprendizado autônomo e personalizado na medida em que se expandem por meio de novos espaços e conversações. 
Averígua-se, também, que os estudantes compreendem que as tecnologias são aliadas aos processos de ensinar e aprender, uma vez que por meio delas e com o auxílio do professor os alunos desenvolveram uma atividade de forma crítica, reflexiva e participativa. Desta forma, e frente a esse cenário tecnológico, o professor passa a dispor de recursos que estimulam a curiosidade e a participação dos estudantes, resultando em reflexões e aprendizados para todos os envolvidos.

Neste desenho, a rede aumenta o sentimento de comunidade educativa, melhorando o ambiente de trabalho e permitindo que o estudante possa criar sua autonomia e sua identidade, intensificando a comunicação entre professores e alunos, facilitando a coordenação do trabalho de diversos grupos de aprendizagem (HARO, 2008), fazendo-se necessário e instigante ampliar a didática dos professores, convidando-os a utilização das tecnologias ao saber dos estudantes, a fim de compartilharem suas descobertas e experiências, incertezas e certezas, refletindo e criando um círculo contínuo de aprendizado via tecnologia.

Destarte, entende-se que as TICs são mecanismos para mediar a educação, tornando-se essenciais à qualificação dos processos de ensino e aprendizagem, uma vez que as novas gerações de estudantes estão cada vez mais conectadas/acopladas a essas novidades. Neste viés, Bedin e Del Pino (2017a, p. 41) refletem que:

[...]há a necessidade de os professores continuarem à busca por uma formação continuada, capaz de proporcionar um conjunto de saberes básicos como forma de viabilizar o diálogo entre os mesmos, a escolas e os estudantes, pois cada vez mais cresce a necessidade de desenvolver trabalhos contextualizados a realidade local.

Ainda, é importante destacar que, por mais que as redes sociais possam, de certa forma, motivar o estudante a buscar e trabalhar com os conteúdos, a fim de decodificar e construir saberes, há de se considerar que as mesmas não são a solução para o caos e os problemas que a educação passa, pois tais ferramentas não visam substituir o ensino em sala de aula, nem o professor, mas auxiliar na busca de um aprendizado mais eficiente, o qual motive os alunos a entender as suas dificuldades e procurar soluções para resolver tais pendências de uma forma diferente da vivenciada.

\section{REFERÊNCIAS}

ABEGG, I.; BASTOS, F da P.; MULLER, F. M. Ensino-aprendizagem colaborativo mediado pelo Wiki do Moodle. Educ. rev. no 38 Curitiba Sept./Dec, 2010. Disponível em: <http://www.scielo.br/scielo.php?pid=S0104-40602010000300014\&script=sci_ arttext $>$ Acesso em: 07 de jan. 2017.

AFONSO, A. S. Uma Análise da Utilização das Redes Sociais em Ambientes Corporativo, 163 f. Dissertação (Mestrado em Tecnologias da Inteligência e Design Digital) Pontifícia Universidade Católica, São Paulo, 2009. 
ALBERTI, E. R. Política de formação de professores mediada pelas tecnologias de informação e comunicação: análise do programa especial de capacitação para docência no estado do Paraná. 2008. 148f. Dissertação (Mestrado em Educação) Universidade Federal do Paraná, Curitiba, 2008.

ALEXANDRE, J. W. C. et al. Análise do número de categorias da escala de Likert aplicada à gestão pela qualidade total através da teoria da resposta ao item. In:

ENCONTRO NACIONAL DE ENGENHARIA DE PRODUÇÃO, 23., 2003, Ouro Preto. Anais... Ouro Preto: [s.1.], 2003.

BALBINO, F. C.; ANACLETO, J. C. Redes Sociais Online Orientadas à Difusão de Inovações como Suporte à Extensão de Práticas Educativas. In: Anais do XXII SBIE XVII WIE, 2011.

BEDIN, E.; DEL PINO, J. C. Desempenho pedagógico: a emersão da interdisciplinaridade na educação básica à luz da reestruturação curricular. Revista Signos, ano 38, n. 1, 2017a. Disponível em: <http://www.univates.br/revistas/index. php/signos/article/view/1251/1137>. Acesso em: 04 de nov. 2017.

BEDIN, E.; DEL PINO, J. C. Sustentabilidade ambiental nas redes sociais: reflexos de uma atividade interdisciplinar. Textura Canoas v. 19 n.41 p. 233-258 Set./dez. 2017b. Disponível em: <http://www.periodicos.ulbra.br/index.php/txra/article/ view/2781/2432>. Acesso em: 04 de nov. 2017.

BRANDALISE, L. T. Modelos de mediação de percepção e comportamento: uma revisão. Disponível em: <http://www.lgti.ufsc.br/brandalise.pdf\&gt>. Acesso em: 11 de jan. 2017.

BRANDTZAEG, P. B.; HEIM, J. Initial context, user and social requirements for the Citizen Media applications: Participation and motivations in off-and online communities. Citizen Media Project, 2007.

BRUNO, A. R. Educação online: aprendizagem do adulto e plasticidade em perspectiva, 2010. In: SILVA, M.; PESCE, L.; ZUIN, A (Orgs). Educação Online: cenário, formação e questões didático-metodológicas. Rio de Janeiro: Wak Editora.

CAPOBIANCO, L. Comunicação e Literacia Digital na Internet - Estudo etnográfico e análise exploratória de dados do Programa de Inclusão Digital Acessa SP - PONLINE. Dissertação (Mestrado em Ciências da Comunicação). Escola de Comunicação e Artes, Universidade de São Paulo, 2010.

CHATTI, M. A.; SRIRAMA, S.; KENSCHE, D.; CAO, Y. Mobile web services for collaborative learning, 2006. In: Wireless, Mobile and Ubiquitous Technology in Education, 2006. WMUTE 06. Fourth IEEE International Workshop on, p. 129-133.

DILLENBOURG, P. Introduction: What Do You Mean By «Collaborative Learning? In: DILlENBOURG, P. (Ed.), Collaborative Learning: Cognitive and Computational 
Approaches. Amsterdam: Pergamon, 1999. Disponível em http://tecfa.unige.ch/tecfa/ publicat/dil-papers-2/Dil.7.1.14.pdf>. Acesso em: 10 jan. 2017.

EDUCAUSE. 7 Things You Should Know About Facebook II, 2007. Disponível em: < http:/ / net.educause.edu/ir/library/pdf/ELI7025.pdf>. Acesso em: 24 dez. 2016.

HARO, J. J. Aplicación de ning a la educación, 2008. Disponível em: < http:/jjdeharo. blogspot.com/2008/11/aplicacin-de-ning-la-educacin.html> Acesso em: 28 dez. 2016.

Redes sociales en educación. In: Jornada Educar para La comunicación y La cooperación social, 2010. Disponível em: <http://jjdeharo.blogspot.com/2010/05/ redes-sociales-en-educacion.html $>$ Acesso em: 03 jan. 2017.

HODGINS, H. W. Into the future a vision paper. In: Commission on Technology and Adult Learning, 2007.

LEMOS, A. Cibercultura, tecnologia e vida social na cultura contemporânea. Porto Alegre: Sulina, 2004.

LITWIN, E. (org.). Tecnologia educacional: política, histórias e propostas. 2. reimp. Tradução Ernani Rosa. Porto Alegre: Artmed, 1997. 191 p.

MASETTO, M. T. Mediação pedagógica e o uso da tecnologia. In: MORAN, J. M.; MASETTO, M. T.; BEHRENS, M. A. Novas tecnologias e mediação pedagógica. 8. ed. Campinas, SP: Papirus, 2006. p.133-173.

MARCON, K.; MACHADO, J. B.; CARVALHO, M. J. S. Arquiteturas Pedagógicas e Redes Sociais: Uma experiência no Facebook. In: Anais do $23^{\circ}$ Simpósio Brasileiro de Informática na Educação. Rio de Janeiro, 2012.

MOLINA, M. P. and Sales, D. Knowledge transfer and information skills for studentcentered learning in spain. Portal: Libraries and the Academy, 2008. 8(1): 53 74.

MORAN, J. M. Ensino e aprendizagem inovadores com tecnologias audiovisuais e telemáticas. In: MORAN, J. M.; MASETTO, M. T.; BEHRENS, M. A. Novas tecnologias e mediação pedagógica. Campinas: Papirus, 2010.

PATRÍCIO, M. R.; GONÇALVES, V. Facebook: rede social educativa? In: I Encontro Internacional TIC e Educação. Lisboa: Universidade de Lisboa, Instituto de Educação, 2010. p. 593-598.

PETTENATI, M. C.; RANIERI, M. Informal learning theories and tools to support knowledge management in distributed CoPs. In: Innovative Approaches for Learning and Knowledge Sharing, EC -TEL. Workshop Proceeding, 2006.

RECUERO, R. Cinco pontos sobre redes sociais na Internet, 2009. Disponível em: <http://www.jornalistasdaweb.com. 
$\mathrm{br} /$ ?pag=displayConteudo\&idConteudoTipo $=2 \&$ idConteudo $=3964>$ Acesso em: 03 jan. 2017.

ROSA, R.; CECÍLIO, S. Educação e o uso pedagógico das tecnologias da informação e comunicação: a produção do conhecimento em análise. Educ. foco, Juiz de Fora, v. 15, n. 1, 2010. p. 107-126.

SILVA, A. P. S. S.; COGO, A. L. P. Aprendizagem de punção venosa com objeto educacional digital no curso de graduação em enfermagem. Revista Gaúcha de Enfermagem. Porto Alegre/RS, v. 28, n. 2, p.185-192, 2007.

TAPSCOTT, D.; WILLIAMS, A. D. Wikinomics: como a colaboração em massa pode mudar o seu negócio. Tradução de Marcello Lino. Rio de Janeiro: Nova Fronteira, 2007.

VYGOTSKY, L. S. A formação social da mente. São Paulo: Martins Fontes, 1998.

WASSERMAN, S.; FAUST, K. Social Netork Analysis: Methods and Applications. Cambridge University Press, 1994.

WERHMULLER, C. M.; SILVEIRA, I. F. Redes Sociais como ferramenta de apoio à Educação. In: Anais do II Seminário Hispano Brasileiro. p. 594-605, 2012.

Disponível em: <http:/ / revistapos.cruzeirodosul.edu.br/index.php/rencima/article/ viewFile/522/446> Acesso em: 23 dez. 2016. 